when it was fully excavated in $1933-34$, it was found to be of unique character in Chinese prehistory. In it were found not only artefacts of an Upper Palæolithic culture, but also the skeletal remains of a number of individuals representative of Upper Palsolithic man in China, who hitherto had been unknown. The results of the excavation of the cave are to be described in a series of monographs, of which that dealing with the archæology by W. C. Pei is the first to appear*.

The Upper Cave, previous to excavation, was completely covered by the superficial soil of the hill and filled with deposits, consisting of a grey loam mixed with fragments of collapsed rock. This was completely removed down to the red and hard breccia of the Choukoutien formation, in which further excavation would have been unprofitable. The cave consists of an upper room, a lower room and a lower recess, a narrow cavity three metres long and one metre wide, forming the lowest part of the cave. Five cultural layers were distinguished. It is possible that the Lower Room, in which human remains, including three complete skulls, were found, may have been a burial place only and not a dwelling site. In the lower recess an accumulation of animal bones and skeletons alone was found.

* The Upper Cave Industry of Choukoutien. By Pei Wen Chung. Palcontologica Sinica, N.S.D., No. 9, 1939, pp. $41+8$ plates.
Occupation lasted up to the complete filling of the upper room. The Upper Cave industry is characterized by a poorly developed, or at least poorly represented, lithic industry in which chert, sandstone, quartz, all foreign to the site but found in the vicinity, are in use. The types of implements include scrapers, choppers, as well as pebble implements. A notable feature is the use of personal ornament-perforated pebbles, stone beads with large perforation and one ground surface. The bone, antler and shell industries, mostly reserved for ornamental purposes, are most characteristic, and being usually left in natural shape are typical of a 'primitive' industry. A remarkable find is a bone needle, such as was not known hitherto to have occurred in China before Neolithic times. The technique of polishing is to be observed on a deer antler and the jaw-bone of a Sika deer.

As a whole, the Upper Cave industry is clearly ranged within an Upper Palæolithic stage, but on comparison with its European equivalents it shows a mixture of relatively primitive and relatively advanced characters. It is likely that these artefacts represent an isolated culture of their own, indebted in part to a northern 'palæarctic' culture, in part to a Pacific culture sheet extending from Malaya to Manchukuo. It may on palæontological and archæological grounds be regarded on the Eastern equivalent of the Western Late Magdalenian.

\title{
FOOD PRODUCTION WITHOUT ARTIFICIAL FERTILIZERS
}

\section{By YSABEL DALDY}

\begin{abstract}
$\mathrm{A}^{\mathrm{s}}$ N ACCOUNT of a valuable experiment in the feeding of schoolboys on vegetables and fruit grown from soil manured exclusively by humus is published by Dr. G. B. Chapman, of the Physical and Mental Welfare Society of New Zealand, Incorporated (Burnock Publications, Auckland, 1939). The locale of the experiment is the Mount Albert Grammar School hostel, the subjects being some sixty boys, teachers and staff. At the time of the inception of the experiment (1936), the dietary at the hostel was liberal, being well above the customary standard for boarding-schools; yet the boys consistently suffered (as was the case in other New Zealand schools and institutions) from colds, catarrh, septic tonsils, epidemics of influenza, dental caries and other preventable complaints. The whole of New Zealand's food supplies are grown from soils manured by the ordinary chemical fertilizers.
\end{abstract}

Dr. Chapman opened his campaign in 1936 by delivering a few short lectures to the resident teachers and boys, advising the growing of the hostel's fruit and vegetables from soils to be treated by properly prepared humus. He was successful in arousing the interest of the teachers, the boys, the matron and the staff. The reform was put in hand and the change-over made from 'chemically grown' fruit, salads and vegetables to the 'naturally produced' foods now in use at the hostel. At the present time, approximately an acre of land is under cultivation for the benefit of the hostel, to the soil (black volcanic) of which no chemical or artificial fertilizers of any kind have been applied. The area in question is supplying the greater proportion of the green vegetables, salad-greens, pumpkins, kumaras, rootvegetables and fruit required by a household of some seventy-seven persons. The following general report of progress in health since the time of the changeover has been submitted by the matron of the hostel (pp. 4-6, "Menus and Recipes", Chapman and Lowe, 1939) :

"The first thing to be noted, during the twelve months following the change-over to garden produce grown from our humus-treated soil, was the declining catarrhal condition among the boys. Catarrh had previously been general and, in some cases, very bad among the boys. In specific cases the elimination was very marked and in many cases complete. There was also a very marked decline in colds and influenza. Colds are now rare and any cases of influenza very mild. Coming to the 1938 measles epidemic, which was universal in New Zealand, the new boys suffered the more acute form of attack; while the boys who had been at the hostel for a year or more sustained the milder attacks, with a much more rapid convalescence.

"During the past three years there has been a marked physical growth and development during terms of heavy school work and sport [actual heights and weights are quoted]. In some cases boys go through a period of indisposition for several weeks after entering the hostel. This would appear to indicate that the method of feeding causes a certain detoxication period which, when cleared up, does not return. Excellent health gradually ensues in all cases, and is maintained. There are fewer accidents, particularly in the football season, which would possibly indicate that the foods in use contain the optimum amount of minerals and vitamins, thus ensuring a full development of bone and muscle and a greater resiliency to fractures and sprains. The 
satisfactory physical condition described is maintained during periods of rapid growth and development of mind and body. Constipation and bilious attacks are rare. Skins are clear and healthy, while the boys are unceasingly active and virile.

"Since the change to naturally grown garden produce, the periodical reports in regard to the boys' dental condition have been more than gratifying." This point needs emphasis, as New Zealanders continue to show a poorer dental condition than is the case in most other countries of the world. In connexion with present-day examinations of young men volunteering for service in the War, the Hon. W. E. Parry, Minister of Internal Affairs, has published the fact (New Zealand Herald, October 2, 1939) that forty per cent of the recruits are found to be temporarily unfit through defective teeth.

Dr. Chapman has now interested the Government of Now Zealand in the results he is obtaining from a dietary inclusive of naturally grown fruit and vegetables; and the Mount Albert Grammar School hostel experiment will in future be continued under the auspices of the New Zealand Health Department.

\section{ORIGIN OF THE VERTEBRATE COELOM By H. BarRaclough FeLl,} (Shirtcliffe Fellow, University of New Zealand)

$\mathrm{R}^{\mathrm{B}}$ ECENT years have witnessed a series of fundamental changes in our ideas on embryology, these changes being the expression of what had formerly been a growing mistrust of some of the generalizations of the nineteenth century. Thus de Beer ${ }^{1}$, in the course of a convincing essay, set forth strong evidence to show that the theory of recapitulation cannot be accepted in its original form. Again, Oppenheimer ${ }^{2}$ has recently reviewed the results of research on the earlier stages of development, and her conclusion is that ". . . the doctrine of the absolute specificity of the germ-layers as enunciated in the last century must be abandoned". So early as 1894, Garstang ${ }^{3}$ had presented evidence leading him to believe that the ancestor of the chordates could be found in an animal closely approximating to the present larval forms of echinoderms. One important consequence of Garstang's work in this direction is that it has led to the recognition of the fact that evolution can act on the earlier stages of development; the original recapitulation theory supposed that evolution worked only on adult forms, tacking on, as it were, additional phases at the end of ontogeny. The echinoderm theory has received ever-increasing attention, until now it may be regarded as the most important attempt to solve the problem of the ancestry of the chordates.

The theory in its present form, however, seems to suffer from one serious drawback, in that it supposes that the schizocoel of vertebrates arose from the enterocoel of the echinoderm larva. It has been urged that the formation of the anterior coelomic pouches from the archenteron in Amphioxus provides evidence of the enterocoelous nature of the original vertebrate coelom. Against this it must be adduced that all known vertebrates have now a schizocoel, and that it is only Amphioxus and its related forms that have an enterocoel. As Amphioxus is in so many ways highly specialized, there can be no safe ground for believing that its mode of derivation of the coelom is primitive. Furthermore, there are other groups of invertebrates, notably the annulates, in which there are strong features of resemblance to the vertebrates, and at the same time a schizocoelous development of the coelom.

It is clear that the above objection applies only so long as we regard the coelom of echinoderms as being necessarily an enterocoel-and, up to the present, there appears to have been no suggestion that this may not be the case. Now, the formation of hollow structures by derivation from pouches does not on the face of it appear to be primitive. Rather it would seem to be a later 'short-circuiting' of some more primitive method which must have involved first the formation of a mass of tissue (in this case mesoderm, derived from endoderm of the archenteron), and secondly the excavation therein of a cavity (in this case the coelom). In the same way it has already been suggested by other workers that the invaginative method of formation of the endoderm and its enclosed cavity the archenteron may be a later short-circuiting of a more primitive scheme in which there first arose a solid mass of endoderm (by migration, delamination, or some other means), and then later the archenteron was excavated in this mass. Invagination in the case of the latter instance, and pouch-formation in the case of the former, are to be regarded as later products of evolution, enabling the final result to be attained in shorter time. One reason for being unable to regard as primitive the pouch method of formation of the coelom is that it is difficult to imagine the incipient stages of such a process, unless we postulate some such previous development as has been outlined.

So far, no practical evidence has been fortheoming to confirm that the enterocoel of the echinoderms is not the only type of coelom found in that group, nor has there been any concrete evidence to show that the echinodern enterocoel may not be primitive. However, in a paper now in the press ${ }^{4}$ it will be shown that the coelom actually does arise by splitting in the mesoderm in a New Zealand ophiuroid. The fact that this species (as yet unidentified) has an unusual development was first discovered and recorded by $\mathrm{Kirk}^{5}$ in 1916, but the schizocoelous origin of its coelom has only recently come to light. This unexpected feature led me to consult a paper by Russo ${ }^{8}$ published as long ago as 1891, in which he claimed to have found that the coelom in the ophiuroid Amphiura squamata arose by splitting in mesenchyme. Owing unfortunately to his inaccurate description and figures, Russo's results were ignored by subsequent workers; but actually he was never proved to be incorrect. His statements, of course, accorded ill with the recapitulation theory then holding sway. I am at present engaged upon a re-investigation of the development of $A$. squamata, and the preliminary results seem to confirm that Russo was indeed right 